\title{
ACCULTURATION, TRAVEL, LIFESTYLE, AND TOURIST BEHAVIOR: A STUDY OF KOREAN IMMIGRANTS IN AUSTRALIA
}

\author{
SUN HEE LEE* and CARMEN COX $\dagger$ \\ *Griffith University, Queensland, Australia \\ $\uparrow$ Southern Cross University, NSW, Australia
}

\begin{abstract}
While tourism research has already considered the specific travel behaviors and preferences of people from different cultures (e.g., Hispanics, Chinese, etc.), there has not been as much emphasis placed on understanding how the travel behaviors of people may change when they migrate to another country. Despite the growth of migrant populations in many countries throughout the world, studies have tended to look at the behavior of travelers from a particular country (e.g., all Australians) without considering how acculturation experienced by migrants (e.g., Koreans who immigrate to Australia) may alter their travel behaviors. This study focuses on the travel behavior and lifestyles of Korean immigrants in Australia and examines the influence of acculturation on their travel lifestyle. A survey of Korean immigrants in Australia was conducted to explore the relationship between the degree of acculturation experienced by respondents and their travel lifestyle preferences, specifically related to their attitudes and opinions towards travel as well as their travel interests. Cluster analysis identified four distinct groups of Korean immigrants, based on their travel lifestyles, referred to as "Korean socializers \& sports seekers," "relaxation seekers," "cultural \& entertainment seekers," and "FIT travel enthusiasts." Results suggest that respondents who were more acculturated significantly differed in their travel lifestyle from those who were less acculturated. The study conclusions suggest ways that tourism marketers can better understand ethnic minorities and develop suitable products and services to meet the needs of these markets.
\end{abstract}

Key words: Acculturation; Travel behavior; Travel lifestyle; Korean immigrants; Australia

\section{Introduction}

Culture has become the focus of attention over the geographical boundaries and disciplines in the 21 st century due to a great number of floating populations resulting from travel, business, or immigration as well as frequent economic, political, and cultural exchanges among countries. A number of studies (Barker, Page, \& Meyer, 2003; Iver- son, 1997; Johns \& Gyimóthy, 2002; Kozak, 2002; March, 1997; Murphy, 2003; Mykletun, Crotts, \& Mykletun, 2001; Pizam \& Jeong, 1996; Pizam et al., 2004; Pizam \& Sussmann, 1995; Reisinger \& Turner, 1998, 1999; 2002a, 2002b, 2003) have sought out the cultural differences with respect to travel behaviors, preferences, motivations, or perceptions. The majority of former studies, however, have used the tourist's nationality as the basis to 
compare the cultural differences among countries. Other studies have used ethnicity to identify the cultural differences within multicultural countries (Irwin, Gartner, \& Phelps, 1990; Klemm, 2002; Manrai \& Manrai, 1995; Tierney, Dahl, \& Chavez, 2001). Nowadays, multiculturalism is a common phenomenon in many countries, including Australia, Canada, and the US, which have been built from large immigrant populations. Hence, issues relating to culture have become a particularly popular area of research in various fields. The issue of migration poses significant opportunities and challenges for the tourism industry. For example, it often leads to a greater level of tourism demand due to people visiting family members who have migrated (or alternatively migrants visiting relatives who they have left behind). Lehto, Morrison, and O'Leary (2001) found that international visitors traveling to see friends and relatives in the US often made substantial use of commercial accommodation and had significant expenditures on food and beverages, transportation, gifts and souvenirs, and entertainment.

Acculturation is defined as "those phenomena which result when groups of individuals having different cultures come into continuous first-hand contact, with subsequent changes in the original cultural patterns of either or both groups" (Redfield, Linton, \& Herskovitz, 1936, cited in Salant $\&$ Lauderdale, 2003, p. 72). One issue that can arise from the effects of acculturation is that migrants who move to a country may have different travel preferences and behaviors to the majority of residents in that country. As such, their travel needs and wants may not be the same as the general resident population and, as such, they may pose a niche market opportunity for tourism operators in the region. The immigrant population is continuously growing in many countries, including Australia. According to the annual report of the Department of Immigration and Multicultural and Indigenous Affairs (2005a), the estimated Australian resident population who were born in the Republic of South Korea was 42,679 as of June 30,2002 . While this is a relatively small population, it continues to increase with an additional 5,000 or more permanent arrivals from Korea recorded to 2004 (Department of Immigration and Multicultural and Indigenous Affairs, 2005b). As such markets continue to grow in Australia (and in other countries also), they may provide the local tourism industries with new opportunities to satisfy their travel needs and enable them to experience a high quality of life through travel opportunities.

Many cross-cultural studies have confirmed that there is a relationship between culture and travel within, and across, countries (Iverson, 1997; Kozak, 2002, Lee, Lee, \& Wicks, 2004; March, 1997; Pizam \& Jeong, 1996). From the results of previous research, it is deduced that travel lifestyle (i.e., the way that people tend to travel as discussed in the next section) can be different among immigrants depending on the extent to which they have experienced acculturation (Stodolska, 1998). Although it may be less distinguishable than the comparison between ethnic groups, understanding how acculturation affects peoples' travel behaviors and lifestyle can only help marketers to better anticipate future market needs in a multicultural society. The objective of this study, therefore, is to explore the effect of acculturation on the travel lifestyles of Korean immigrants in Australia.

\section{Travel Lifestyle Segmentation}

Over the last few decades more heterogeneous, individualistic, and culturally diverse consumers' needs and expectations have added to the importance of market segmentation (Middleton \& Clarke, 2001). While demographic characteristics have been commonly used to segment markets and have been found to have some predictive use in anticipating the travel behavior of different market segments, it may no longer be an effective market segmentation tool by itself as consumers are becoming more diversified. In the 1990s, Prentice, Witt, and Hamer (1998) found that demographic variables were largely irrelevant in understanding the Rhondda Heritage Park visitors' experiences. Milman (1991) also found no correlation between demographics and theme park visitation patterns, and Andereck and Caldwell (1994) also reiterated that there was little difference between demographic segments of the zoological park market. Hence, more researchers and marketers have turned to various other segmentation variables such as personality, motivations, attitudes, values, and life- 
style in association with demographic characteristics.

Weinstein (1994) noted the advantages of using psychographic segmentation for target market identification beyond demographics. He argued that information can be used in planning successful marketing strategies, and in minimizing risk through incorporating psychographics into product developing and testing. Lifestyle is defined as "the system of behaviour patterns of an individual or a group of people which results from the (sometimes involuntary) hierarchy of values recognized by the individual or the group of people" (Przeclawski, 1988, p. 36), or "a system of individual differences in the usual use of declarative and procedural knowledge structures that interfere between abstract goal states (personal values) and situationspecific product perceptions and behaviours" (Brunsø, Scholderer, \& Grunert, 2004, p. 665). Lifestyle is commonly used as a psychographic segmentation tool and has been widely used to segment the target market into homogeneous groups with similar preference for products or services in the tourism industry (Darden \& Perrault, Jr., 1975; Lawson, Thyne, Young, \& Juric, 1999; Schul \& Crompton, 1983). Lifestyle research uses questions about activities/attitudes, interests, and opinions (AIO) as a way of finding out why consumers choose a particular product or, in the case of tourism, why tourists choose a particular destination or type of holiday (Gountas \& Gountas, 2001). Darden and Perreault (1975), for example, found that the type of vacation taken, as well as a person's patterns of media exposure, were compatible with their lifestyle (activities, interests, and opinions). Moreover, Perreault, Darden, and Darden (1977) confirmed the existence of generalized "vacation lifestyles" and a relationship with sociological variables. Schul and Crompton (1983) noted that travel search behavior can also be explained by a person's travel lifestyle. Furthermore, Silverberg, Backman, and Backman (1996) utilized lifestyle characteristics to identify the differences between natured-based travelers and, similarly, Gladwell (1990) used lifestyle to explore the behavior of general park users. Although there is some evidence of travel lifestyle being an effective segmentation tool for identifying target markets in previous research, there is a lack of studies that have applied travel lifestyle to segment markets based on ethnic groups and acculturation levels.

\section{Acculturation}

The marketing literature notes that culture plays an important role in consumer behavior through its impact on consumers' values and lifestyle (Henry, 1976; Kamo \& Zhou, 1994; McCracken, 1988). Cultural values are central to any ethnic group, and culture is the configuration of learned behavior, results of behavior, and the distinctive lifestyle of a society (McCullough, Tan, \& Wong, 1986; Tan \& McCullough, 1985). Thus, a group of consumers from the same culture have many things in common-not only their outward appearance, but also their thoughts and behaviors. In the tourism discipline, cultural differences have been testified through the comparison of tourist behaviors by nationality or ethnicity in many studies (Iverson, 1997; Kozak, 2002, Lee et al., 2004; March, 1997; Pizam \& Jeong, 1996). However, the study of the effect of acculturation on travel lifestyle has received little attention. Understanding the effect of acculturation seems useful to predict market changes likely to occur in relation to ethnic minorities in a multicultural society. It is also useful for development of appropriate marketing strategies if marketers understand how people may change their behavior through the process of acculturation.

It is known that culture influences lifestyle, including gender roles in everyday life. Kim, Laroche, and Tomiuk (2001), for example, examined the relationships between acculturation and some aspects of gender role perceptions of Italian Canadian spouses and it was revealed that more acculturated Italian Canadian spouses tended to hold more modern sex role attitudes and developed domestic task role expectations such as more husband involvement in the household tasks. Furthermore, McCracken (1988) stated that consumption is a thoroughly cultural phenomenon, so it is shaped, driven, and constrained by cultural consideration. Therefore, changes resulting from an encounter with another culture (i.e., acculturation) should directly affect consumption activities. Henry (1976) obtained statistical results that provided empirical support for the commonly held 
theory that culture is one of the underlying determinants of consumer behavior. Juniu (2000) also found evidence that some lifestyle changes occurred in a selected group of South American immigrants after they had migrated to the US. This was observed in the participants' socialization patterns, their views about work, and their perception of time. Furthermore, these changes had an impact on their leisure experience and recreation participation (Juniu, 2000).

Culture is neither uniform nor static and it is a continual synthesis of old and new in many changes of society as well as many modes of exchange between societies (Sherry, 1986). Thus, the behavior of immigrants can be changed by acculturation in their new country unless they have difficulties in adopting the culture of the new country for some reason. Existing research of Confucian values among Koreans and Korean Americans revealed that Korean immigrants who had experienced adaptive limitations or prejudice and discrimination in the US did not endorse traditional values as strongly as those without such experiences (Hyun, 2001). These experiences tended to result in one of two opposite attitudes in the life of immigrants. They either tended to reduce the degree of interaction among members of different cultures (Reisinger \& Turner, 2003) or they tended to assimilate quickly into the new culture. Boekestijn (1988) found that most previous research has found that migrants tend to affiliate well with coculturals in the country which they have migrated to. Only one study (Alexander, 1969, cited in Boekestijn, 1988) has referred to the tendency of some immigrants to avoid contact with conationals in order to assimilate as quickly as possible.

According to Johansson and Miegel (1992), lifestyle strongly depends on cultural identity. Tse, Wong, and Tan (1988) also emphasized cultural values as a tool that shapes consumers' motivation, lifestyle, and product choices. The current study arises, therefore, from the question of "how acculturation affects the travel lifestyle of Koreans who have migrated to, and are now living in, Australia." This study therefore aims to explore the relationship between travel lifestyle and acculturation among Korean immigrants in Australia in order to validate cultural influences on the consumers' travel lifestyle (i.e., their activities, interests, and opinions related to travel).

\section{Methodology}

A self-administered questionnaire was developed to collect data for this study. The questionnaire consisted of three sections to find out about the respondents' (i) travel lifestyle: (ii) degree of acculturation; and (iii) demographic characteristics.

Where possible, existing scales developed by previous researchers were used to ensure that the most reliable, valid, and rigorously tested measures of each issue (e.g., acculturation) were incorporated in the current study. The lifestyle statements were adapted from the AIO scale originally developed by Perreault et al. (1977) and later applied to the specific context of travel lifestyle by Schul and Crompton (1983) and Silverberg et al. (1996). The resulting 25 lifestyle statements were measured using a 7-point Likert scale $(1=$ strongly disagree to $7=$ strongly agree) .

The acculturation scale developed and used to study Italian Canadians by Kim et al. (2001) was used to assess acculturation. This scale, containing 27 items, was considered suitable for this study of Korean immigrants in Australia; thus, it was adapted with partial modification resulting from a pilot test with 30 Korean students who were living in Australia for the duration of their undergraduate degrees. The acculturation questions were also measured using the same 7-point scale as the lifestyle measures.

Demographic information collected included age, gender, marital status, level of education, and income. Additionally, questions about English language proficiency, length of stay in Australia, and the ethnicity of the respondent's marriage partner were also included in the questionnaire.

The questionnaire was initially designed in English, and then translated into Korean individually by two Korean-English bilinguals. After its modification through comparison of differences in the translation, another bilingual person carried out back translation, and some modifications were also made based on a comparison between the original English version of questionnaire and the back-translated version of questionnaire. A pilot test was conducted with Korean university students in Australia to ensure accuracy and logic in the phrasing of questions.

As low response rates to mail surveys (less than $10 \%$ of response rates) are prevalent in studies that 
have surveyed Koreans (Chen \& Hsu, 2000; Pizam \& Jeong, 1996), an on-site survey was chosen for this study. Due to the difficulty in accessing a large number of Korean-born residents in Australia in a systematic manner, the survey was conducted at Korean worship places (e.g., Korean churches and temples) and Korean shops on the Gold Coast and in Brisbane. These places were considered the most likely places to access a large number of Korean Australians at one time due to the absence of social clubs or regular meetings among Korean community on the Gold Coast and in Brisbane. Thus, the respondents were also limited to those Korean immigrants who participated in Korean communities, such as Korean churches and temples. In other words, Korean immigrants who did not make contact with other Koreans in Australia might not be included in this study. Presumably Korean immigrants who married members of other ethnic groups and are completely assimilated into Australian society were less likely to be involved with the Korean community in Australia. While, due to the collection methods used, the respondents in this study may not have been fully representative of Korean immigrants in Australia, a comparison to the Australian Bureau of Statistics (2001) census data, as discussed briefly in the results section, suggests that those surveyed in this study were relatively representative of the population of Korean-born residents living in Australia.

The researchers went to the venues and made an announcement to explain the purpose of the study and to ask participation in the survey. The data were collected from residents aged over 20 years, who were born in Korea, but who had migrated to Australia and had become permanent residents or citizens of Australia. As participation in the research was voluntary in nature, surveys were only given out to those present who volunteered to collect one following the announcements being made. As such, given the environment where people were free to come and go at their leisure, making head counts difficult to conduct, it is difficult to estimate the exact response rate from all who were present at the worship place. Of the 317 questionnaires that were distributed and returned by respondents, 272 questionnaires were considered "complete" and useable in the analysis. This suggests a $73 \%$ useable response rate from the sur- veys distributed to willing participants, with the remaining surveys either not completed or unreturned to the researcher. Table 1 presents the demographic characteristics of respondents.

\section{Results}

Following a review of the demographic profile of respondents provided in Table 1, the latest available (2001) Australian census figures were reviewed to compare the representativeness of the sample, where feasible, against characteristics of all Korean-born residents living in Australia. The gender balance is relatively similar, with females accounting for a slightly higher percentage of residents than males in the Korean community. It is difficult to compare the age representativeness as the current study adopted different age categories than were collected in the 2001 census; however, the results are shown in Table 1. Both the length of residency in Australia and the level of English language proficiency appear to be relatively similar between those surveyed in this study and the overall population figures. As such, the sample of Korean immigrants surveyed in this research appear to be relatively representative of the population residing in Australia overall (notwithstanding that the most recent census data available is now over 5 years old).

The data analysis of this study consisted of four steps. Firstly, factor analysis was conducted for both the travel lifestyle and acculturation scales. Secondly, cluster analysis was performed to segment Korean immigrants with distinctive travel lifestyle characteristics. Thirdly, ANOVA tests were conducted to explore the relationship between acculturation and travel lifestyle. Finally, chi-square tests were performed to investigate the differences among clusters based on demographic variables and other travel behavior variables.

\section{Travel Lifestyle}

To identify the underlying factors of travel lifestyle, factor analysis was performed using principal components analysis with orthogonal rotation (varimax). The items with factor loadings greater than 0.4 were subjected to factor analysis. The initial 25 items contained in the travel lifestyle scale were reduced to eight underlying factors. Table 2 presents the results of the factor analysis including 
Table 1

Demographic Characteristics of Respondents

\begin{tabular}{|c|c|c|}
\hline Demographic Characteristics & $\begin{array}{c}\% \text { of } \\
\text { Respondents }\end{array}$ & $\begin{array}{l}\text { ABS Census Data } \\
\text { (\% Korean-Born } \\
\text { Residents, 2001) }\end{array}$ \\
\hline \multicolumn{3}{|l|}{ Gender } \\
\hline Male & 40.4 & 47 \\
\hline Female & 59.6 & 53 \\
\hline \multicolumn{3}{|l|}{ Age } \\
\hline $20-29$ years (ABS $15-25$ years) & 21.7 & 25 \\
\hline $30-39$ years (ABS $23-34$ years) & 32.7 & 27 \\
\hline $40-49$ years (ABS $35-44$ years) & 34.2 & 22 \\
\hline $50-59$ years (ABS $45-64$ years) & 7.4 & 21 \\
\hline 60 years and over (ABS 65 years and over) & 4.0 & 4 \\
\hline Marital status & & NA \\
\hline Never married & 19.9 & \\
\hline Married/de facto & 78.3 & \\
\hline Widow/widower & 1.1 & \\
\hline Divorced/separated & 0.7 & \\
\hline Education & & NA \\
\hline Postgraduate (master or Ph.D.) & 14.3 & \\
\hline Bachelor degree & 66.9 & \\
\hline Senior high school or less & 17.6 & \\
\hline Missing & 1.1 & \\
\hline Income & & NA \\
\hline Less than $\mathrm{A} \$ 20,000$ & 20.2 & \\
\hline $\mathrm{A} \$ 20,000-\$ 39,999$ & 26.8 & \\
\hline $\mathrm{A} \$ 40,000-\$ 69,999$ & 26.5 & \\
\hline $\mathrm{A} \$ 70,000-\$ 99,999$ & 7.0 & \\
\hline $\mathrm{A} \$ 100,000-\$ 149,999$ & 5.1 & \\
\hline $\mathrm{A} \$ 150,000$ or more & 2.2 & \\
\hline Missing & 12.1 & \\
\hline \multicolumn{3}{|l|}{ Length of stay in Australia } \\
\hline Less than 1 year & 7.4 & 8 \\
\hline $1-2$ years & 11.4 & 18 \\
\hline $3-4$ years & 19.5 & 12 \\
\hline $5-9$ years & 34.6 & \\
\hline 10 years or more & 27.2 & $62^{\mathrm{a}}$ \\
\hline \multicolumn{3}{|l|}{ English proficiency } \\
\hline No English at all & 2.9 & 5 \\
\hline A little/poor & 28.3 & 33 \\
\hline Intermediate/fair & 36.4 & \\
\hline Good & 23.9 & $62^{\mathrm{b}}$ \\
\hline Very fluent/perfect & 8.5 & \\
\hline Ethnicity of marriage partner & & NA \\
\hline Korean & 93.3 & \\
\hline Non-Korean & 6.7 & \\
\hline
\end{tabular}

${ }^{a} \mathrm{ABS}$ equivalent to 5 or more years since arriving in Australia.

${ }^{\mathrm{b}} \mathrm{ABS}$ equivalent to speaks/understands English well/very well.

items, factor loadings, eigenvalues, and Cronbach's alpha scores. The Kaiser-Meyer-Olkin Measure of Sampling Adequacy was 0.72. The Bartlett's Test of Sphericity (Bartlett, 1954) showed statistical significance $(p=0.000)$. Reliability analysis was performed to test internal consistency of each factor. All eight factors showed Cronbach's alpha scores of 0.60 or above. Although desirable to have alpha scores of 0.7 or greater to consider a scale a "good" measure, scores of 0.6 or more are considered to be satisfactory for exploratory research (Hair, Anderson, Tatham, \& Black, 1998). The eight factors explained $65 \%$ of the variance overall. These factors are used later in the analysis to present a segmentation of Korean immigrants based on their travel lifestyle. 


\section{Acculturation}

Using the same methods presented in the previous section, factor analysis was also carried out to identify a set of underlying factors of acculturation. The results, presented in Table 3, suggest a five-factor solution, with the factors being labeled as "Korean Attachment," "English Language Use," "Australian Social Interaction and Mass Media Exposure," "Australian Attachment and Identification," and "Korean Identification." The KaiserMeyer-Olkin Measure of Sampling Adequacy was
0.883 and the Bartlett's Test of Sphericity reached statistical significance $(p=0.000)$. The five-factor solution explained $72 \%$ of overall variance. The reliability of the variables in each factor was again tested using Cronbach's alpha coefficients. Cronbach's alphas of the five factors were all above 0.85 , which suggests the scales were excellent measures of the dimensions of acculturation (Hair et al., 1998).

In order to segment respondents based on their travel lifestyle, a two-step cluster analysis was conducted. In the first step, hierarchical cluster

Table 2

Travel Lifestyle Factors

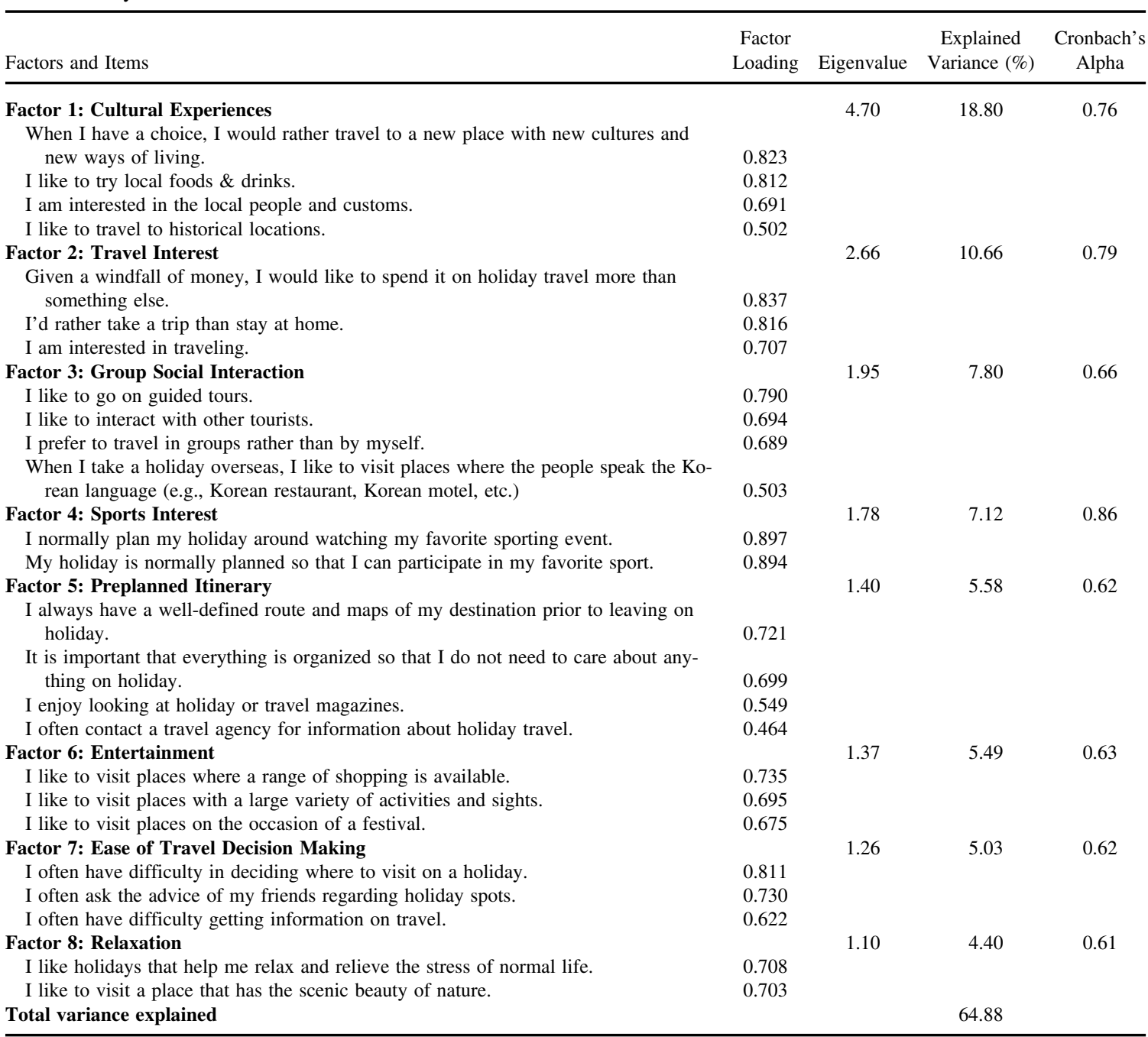


Table 3

Acculturation Factors

\begin{tabular}{|c|c|c|c|c|}
\hline Factors and Items & $\begin{array}{l}\text { Factor } \\
\text { Loading }\end{array}$ & Eigenvalue & $\begin{array}{c}\text { Explained } \\
\text { Variance }(\%)\end{array}$ & $\begin{array}{c}\text { Cronbach's } \\
\text { Alpha }\end{array}$ \\
\hline Factor 1: Korean Attachment & & 8.58 & 31.77 & 0.91 \\
\hline I feel very proud of the Korean culture. & 0.863 & & & \\
\hline I feel a strong attachment to the Korean culture. & 0.855 & & & \\
\hline I feel most comfortable in the Korean culture. & 0.853 & & & \\
\hline I feel very proud to identify with Koreans. & 0.799 & & & \\
\hline I consider the Korean culture rich and precious. & 0.735 & & & \\
\hline The Korean culture has the most positive impact on my life. & 0.649 & & & \\
\hline Factor 2: English Language Use & & 5.23 & 19.35 & 0.92 \\
\hline In general, I speak in English. & 0.795 & & & \\
\hline I always use English with my friends. & 0.777 & & & \\
\hline I mostly think in English. & 0.775 & & & \\
\hline I always speak English to my spouse. & 0.771 & & & \\
\hline I mostly speak in English at family gatherings. & 0.770 & & & \\
\hline I mostly carry on conversations in English everyday. & 0.718 & & & \\
\hline Factor 3: Australian Social Interaction and Mass Media Exposure & & 3.08 & 11.40 & 0.89 \\
\hline Most of the people at the places I go to have fun and relax are Caucasian. & 0.782 & & & \\
\hline Most of my friends are Caucasian. & 0.779 & & & \\
\hline I get together with Caucasian very often. & 0.778 & & & \\
\hline I have many Caucasian friends with whom I am very close. & 0.756 & & & \\
\hline The movies and videocassettes that I watch are mostly in the English language. & 0.637 & & & \\
\hline The newspapers and magazines that I read are mostly in the English language. & 0.624 & & & \\
\hline Factor 4: Australian Attachment and Identification & & 1.35 & 4.99 & 0.90 \\
\hline I feel a strong attachment to the Australian culture. & 0.872 & & & \\
\hline I feel very proud of the Australian culture. & 0.858 & & & \\
\hline I consider the Australian culture rich and precious. & 0.828 & & & \\
\hline I feel most comfortable in the Australian culture. & 0.779 & & & \\
\hline I feel very proud to identify with Australians. & 0.765 & & & \\
\hline The Australian culture has the most positive impact on my life. & 0.611 & & & \\
\hline Factor 5: Korean Identification & & 1.21 & 4.50 & 0.87 \\
\hline I consider myself to be Korean. & 0.878 & & & \\
\hline I would like to be known as "Korean" by people of Korean descent. & 0.822 & & & \\
\hline I have the sentiment of "Korean." & 0.713 & & & \\
\hline Total variance explained & & & 72.01 & \\
\hline
\end{tabular}

analysis was used to identify the appropriate number of clusters using Ward's method. In the second step, K-means cluster analysis was conducted using the hierarchical results as a basis for generating the seed points. As shown in Table 4, this process resulted in four clusters being considered as the most appropriate solution from a series of two to six cluster solutions.

Cluster 1, Korean Socializers and Sports Seekers (15\% of respondents), showed the highest factor scores on "group social interaction" and "sports interest" but relatively low factor scores on "cultural experiences," "preplanning," "entertainment," "ease of travel decision making," and "relaxation." The respondents in this cluster tended to be only interested in participating in sports activities while traveling rather than sight- seeing, relaxation, or gaining new experiences. They were less likely to preplan their travel and had difficulty making decisions about what destinations to visit.

Cluster 2, Relaxation Seekers (36\% of respondents), is the largest segment. They recorded the highest factor scores on "relaxation" and relatively high scores on "group social interaction" and "preplanned itineraries." Overall they had relatively low interest in travel and recorded negative scores on "cultural experiences," "sports interest," and "entertainment." The respondents in this cluster were more likely to plan their travel to take a rest and relax in a secure way rather than participating in activities and sightseeing.

Cluster 3, Culture and Entertainment Seekers ( $21 \%$ of respondents), had the highest scores on 
"preplanning," "entertainment," "cultural experiences," and "ease of travel decision making," but the lowest score on "relaxation." The people in this group were neutral about sports interests and negative about the preference for group social interaction or travel for relaxation. They tended to have a well-planned travel itinerary, although they experienced some difficulty in obtaining travel information. They were likely to seek new experiences and a variety of entertainment such as festivals and shopping when they travel.

Cluster 4, FIT Travel Enthusiasts (28\% of respondents), was the second largest of the four clusters. The respondents in this cluster had a high interest in traveling and expressed a range of interests from cultural experiences, sporting interests, and socializing to simply relaxing. The people in this group were less likely to preplan their travel and were more likely to travel by themselves.

\section{The Effects of Acculturation on Travel Lifestyle of Migrants}

One-way ANOVA tests were conducted to examine the relationship between the types of travel lifestyle adopted and the level of acculturation of respondents in each cluster. As shown in the bottom half of Table 4, the ANOVA tests indicate that there were significant differences on three factors of acculturation between the four clusters: "Australian Social Interaction and Mass Media Exposure" $[F(3,240)=4.05, p<0.01]$, "Australian Attachment and Identification" $[F(3,240)=$ $6.13, p<0.001]$, and "Korean Identification" $[F(3$, $240)=4.16, p<0.01]$.

Post hoc comparisons using the Tukey HSD test indicated that there was a significant difference between the "FIT Travel Enthusiasts" (mean $=0.30$, $\mathrm{SD}=1.00$ ) and the "Relaxation Seekers" (mean = $-0.22, \mathrm{SD}=0.90, p<0.01$ ) in terms of "Australian Social Interaction and Mass Media Exposure." There was also a difference between the "FIT Travel Enthusiast" ( mean $=0.34, \mathrm{SD}=0.87$ ) and the "Korean Socializer and Sports Seekers" (mean $=-0.50, \mathrm{SD}=0.96, p<0.001)$ in terms of "Australian Attachment and Identification." The "Relaxation Seekers" $($ mean $=0.21, \quad \mathrm{SD}=0.86)$ were also significantly different from the "Korean Socializer and Sports Seekers" (mean $=-0.34$, SD $=1.30, p<0.05)$ and the "Culture and Entertain-

Table 4

Profile of Clusters by Travel Lifestyle and Acculturation

\begin{tabular}{|c|c|c|c|c|c|c|}
\hline $\begin{array}{c}\text { Korean } \\
\text { Socializers } \\
\text { \& Sports } \\
\text { Seekers } \\
(15 \%)\end{array}$ & $\begin{array}{c}\text { Relaxation } \\
\text { Seekers } \\
(36 \%)\end{array}$ & $\begin{array}{c}\text { Culture \& } \\
\text { Entertainment } \\
\text { Seekers } \\
(21 \%)\end{array}$ & $\begin{array}{c}\text { FIT Travel } \\
\text { Enthusiasts } \\
\quad(28 \%)\end{array}$ & $d f$ & $F$ & Sig. \\
\hline-1.00 & -0.09 & 0.33 & 0.40 & $271(3,268)$ & 25.80 & $0.000 *$ \\
\hline 0.09 & -0.38 & -0.03 & 0.46 & $271(3,268)$ & 11.47 & $0.000^{*}$ \\
\hline 0.64 & 0.45 & -0.21 & -0.76 & $271(3,268)$ & 39.37 & $0.000^{*}$ \\
\hline 0.61 & -0.44 & -0.07 & 0.28 & $271(3,268)$ & 15.46 & $0.000 *$ \\
\hline-0.65 & 0.24 & 0.78 & -0.54 & $271(3,268)$ & 37.66 & $0.000^{*}$ \\
\hline-0.15 & -0.20 & 0.45 & 0.00 & $271(3,268)$ & 5.78 & $0.001 *$ \\
\hline-0.29 & 0.07 & 0.18 & -0.08 & $271(3,268)$ & 2.11 & 0.099 \\
\hline-0.74 & 0.57 & -0.94 & 0.37 & $271(3,268)$ & 66.75 & $0.000 *$ \\
\hline 0.13 & -0.03 & 0.03 & -0.05 & $243(3,240)$ & 0.29 & 0.835 \\
\hline-0.12 & -0.05 & 0.23 & -0.06 & $243(3,240)$ & 1.25 & 0.292 \\
\hline-0.17 & -0.22 & 0.09 & 0.30 & $243(3,240)$ & 4.05 & $0.008 * *$ \\
\hline-0.50 & -0.09 & 0.03 & 0.34 & $243(3,240)$ & 6.13 & $0.000 *$ \\
\hline-0.34 & 0.21 & -0.25 & 0.10 & $243(3,240)$ & 4.16 & $0.007 * *$ \\
\hline
\end{tabular}

The cluster descriptors are based on the factor scores that were derived from travel-specific lifestyle data and have a mean of zero and SD of 1 .

${ }^{a}$ One-way ANOVA tests with significant level at: $* p<0.001$ and $* * p<0.01$. 
ment Seekers" $\quad($ mean $=-0.25, \quad \mathrm{SD}=0.96, \quad p<$ $0.05)$ with respect to "Korean identification."

The "FIT Travel Enthusiast" appeared to have the highest level of "Australian Social Interaction and Mass Media Exposure," which may explain why they also had a stronger "Australian Attachment and Identification" than the other clusters. On the other hand, the "Relaxation Seeker" had the lowest levels of "Australian Social Interaction and Mass Media Exposure," but they had the strongest sense of "Korean identification." The "Relaxation Seekers" had positive attitudes toward social interaction as this cluster reports positive scores on the "group social interaction" factor, which is related to their preference for group tours. The "Korean Socializers and Sports Seekers" had the lowest levels of both "Australian Attachment and Identification" and "Korean identification" compared to other clusters. In essence, this group was still relatively more attached to Korean culture than the other clusters. They tended not to use English as much and did not seem to mix regularly with non-Korean Australians in general. As such, it is perhaps not surprising to note that the travel they did undertake tended to be in groups with other Koreans (and largely related to sporting interests).

\section{Demographic Profile and Travel Experiences of the Segments}

Chi-square tests were conducted to examine the differences between the clusters using demographic characteristics. As shown in Table 5, the results revealed that there were significant differences in gender $\left[\chi^{2}(3)=19.36, p<0.001\right]$ and education $\left[\chi^{2}(6)=14.12, p<0.05\right]$ across the clusters. The proportion of males in the "Korean Socializer and Sports Seeker" cluster was noticeably greater than females, while the proportion of females in the "Relaxation Seeker" and "Culture and Entertainment Seeker" clusters was distinctly greater than males. In terms of education, more educated people tended to be the "Culture and Entertainment Seekers" or "FIT Travel Enthusiasts." There were no significant differences in terms of age, marital status, or income across the clusters.

In addition to demographic characteristics, chisquare tests were conducted for English language proficiency and the length of residency in Australia. The results (see Table 5) revealed no significant differences in either English proficiency ( $p=$ $0.138)$ or in the length of residency in Australia $(p=0.540)$ across the clusters. This suggests that neither English language proficiency nor the length of time spent living in Australia had any real effect on respondents' travel lifestyle.

In terms of how the four clusters differed in their actual travel experiences, Table 5 also provides a comparison of how respondents felt their frequency of travel had changed since migrating to Australia, along with the types of travel (domestic vs. international) they tended to participate in. As shown, there were no significant differences reported on the change in the frequency of travel since moving to Australia among the clusters ( $p=$ 0.114). While a substantial proportion (e.g., 30$49 \%$ ) of all clusters did report that they had encountered some inconveniences when traveling due to language or other cultural barriers since moving to Australia, there was no significant difference between the clusters $(p=0.06$ and 0.12 , respectively). There was, however, a noticeable and significant difference reported by the different clusters about how frequently they holidayed in Australia $(p=0.027)$ and how often the holidayed overseas $(p=0.005)$, with the "Culture and Entertainment Seekers" and the "FIT Travel Enthusiasts" reporting much more regular trip patterns compared to the other two clusters who tended to travel less in general.

\section{Implications and Conclusions}

According to the results of this study, there is some empirical evidence to support the idea that different acculturation experiences of migrants can affect their resulting travel lifestyle (as measured by their reported travel attitudes, opinions, and interests). While the majority of Korean migrants surveyed in the study did not believe that their move to Australia had altered their frequency of travel overall, some of the other results do suggest a significant link between their acculturation levels since migrating and the type of travel behavior and lifestyle they are now most likely to adopt.

From the cluster analysis reported previously, it is evident that the two most active travel seg- 
Table 5

Profile of Segments Based on Demographics and Travel Behavior

\begin{tabular}{|c|c|c|c|c|}
\hline & \multicolumn{4}{|c|}{$\%$ Within Cluster } \\
\hline & $\begin{array}{l}\text { Korean } \\
\text { Socializers } \\
\text { \& Sports } \\
\text { Seekers }\end{array}$ & $\begin{array}{c}\text { Relaxation } \\
\text { Seekers }\end{array}$ & $\begin{array}{c}\text { Culture \& } \\
\text { Entertainment } \\
\text { Seekers }\end{array}$ & $\begin{array}{l}\text { FIT Travel } \\
\text { Enthusiasts }\end{array}$ \\
\hline \multicolumn{5}{|l|}{ Gender $\left(\chi^{2}=19.36, p=0.000 *\right)$} \\
\hline Male & 63 & 35 & 23 & 48 \\
\hline Female & 37 & 65 & 77 & 52 \\
\hline \multicolumn{5}{|l|}{ Age $\left(\chi^{2}=9.77, p=0.135\right)$} \\
\hline $22-29$ years & 17 & 19 & 35 & 18 \\
\hline $30-39$ years & 37 & 30 & 33 & 34 \\
\hline 40 years and over & 46 & 52 & 32 & 48 \\
\hline \multicolumn{5}{|l|}{ Marital status $\left(\chi^{2}=6.91, p=0.075\right)$} \\
\hline Never married & 15 & 17 & 33 & 18 \\
\hline Married/de facto & 85 & 83 & 67 & 82 \\
\hline \multicolumn{5}{|l|}{ Education $\left(\chi^{2}=14.12, p=0.028^{* *}\right)$} \\
\hline Postgraduate (master or Ph.D.) & 5 & 9 & 21 & 21 \\
\hline Bachelor degree & 78 & 70 & 55 & 68 \\
\hline Senior high school or less & 17 & 21 & 23 & 11 \\
\hline \multicolumn{5}{|l|}{ Income $\left(\chi^{2}=13.18, p=0.155\right)$} \\
\hline Less than $\mathrm{A} \$ 20,000$ & 19 & 24 & 31 & 18 \\
\hline A $\$ 20,000-\$ 39,999$ & 22 & 33 & 31 & 32 \\
\hline $\mathrm{A} \$ 40,000-\$ 69,999$ & 44 & 31 & 27 & 24 \\
\hline $\mathrm{A} \$ 70,000$ or more & 14 & 12 & 11 & 27 \\
\hline \multicolumn{5}{|l|}{ Length of residency in Australia $\left(\chi^{2}=7.95, p=0.540\right)$} \\
\hline 2 years or less & 24 & 19 & 18 & 17 \\
\hline $3-4$ years & 17 & 24 & 16 & 18 \\
\hline $5-9$ years & 32 & 29 & 47 & 34 \\
\hline 10 years or more & 27 & 29 & 19 & 31 \\
\hline \multicolumn{5}{|l|}{ English proficiency $\left(\chi^{2}=9.70, P=0.138\right)$} \\
\hline No English at all/a little & 32 & 38 & 35 & 20 \\
\hline Intermediate/fair & 39 & 36 & 28 & 41 \\
\hline Good or very fluent/perfect & 29 & 26 & 37 & 39 \\
\hline \multicolumn{5}{|l|}{ Change in travel frequency $\left(\chi^{2}=5.95, p=0.114\right)$} \\
\hline Travel more than when living in Korea & 32 & 52 & 51 & 42 \\
\hline \multicolumn{5}{|l|}{ Experience of language barriers $\left(\chi^{2}=7.65, p=0.060\right)$} \\
\hline Have experienced inconvenience when traveling due to language & 32 & 49 & 40 & 30 \\
\hline \multicolumn{5}{|l|}{ Experience of cultural barriers $\left(\chi^{2}=5.84, p=0.120\right)$} \\
\hline Have experienced inconvenience when traveling due to culture & 32 & 39 & 49 & 30 \\
\hline \multicolumn{5}{|l|}{ Frequency of holiday in Australia $\left(\chi^{2}=18.78, p=0.027\right)$} \\
\hline Never & 24 & 13 & 4 & 8 \\
\hline Less than once a year & 34 & 43 & 41 & 33 \\
\hline $1-2$ times a year & 42 & 40 & 44 & 53 \\
\hline 3 or more times a year & 0 & 4 & 11 & 6 \\
\hline \multicolumn{5}{|l|}{ Average length of holiday in Australia $\left(\chi^{2}=1.99, p=0.921\right)$} \\
\hline $1-6$ days & 77 & 83 & 76 & 79 \\
\hline $1-2$ weeks & 21 & 15 & 19 & 18 \\
\hline More than 2 weeks & 2 & 2 & 5 & 3 \\
\hline \multicolumn{5}{|l|}{ Frequency of overseas holiday $\left(\chi^{2}=23.33, p=0.005\right)$} \\
\hline Never & 25 & 13 & 16 & 5 \\
\hline Less than once a year & 35 & 51 & 35 & 29 \\
\hline $1-2$ times a year & 35 & 30 & 40 & 51 \\
\hline 3 or more times a year & 5 & 6 & 9 & 15 \\
\hline \multicolumn{5}{|l|}{ Average length of holiday overseas $\left(\chi^{2}=27.62, p=0.000\right)$} \\
\hline $1-6$ days & 61 & 24 & 26 & 27 \\
\hline $1-2$ weeks & 28 & 45 & 25 & 40 \\
\hline More than 2 weeks & 11 & 31 & 49 & 33 \\
\hline
\end{tabular}

Significant level at: $* p<0.001$ and $* * p<0.05$. 
ments (the "Culture and Entertainment Seekers" and the "FIT Travel Enthusiasts"), in terms of both their self-reported interest in travel and their tendency to enjoying both cultural experiences and entertainment when they travel, also reported having the highest levels of social interaction and mass media exposure with Australian culture. They also reported feeling more attached to Australia and identifying with the Australian culture, although it is noted that the latter group also had a positive sense of Korean identification. Both groups also tended to use the English language in their everyday lives more than the two less active travel clusters.

There appears to be several important considerations for tourism operators and marketers (both in Australia and elsewhere) to note from the results reported above. Firstly, simply being aware that not all Korean immigrants who live in one country will tend to enjoy or desire the same travel experiences as each other, even though they originate from the same cultural background. As demographic factors such as age and income do not seem to explain the differences in travel lifestyle, it seems valid to suggest that the different degrees of acculturation experienced by individual immigrants do in fact have a distinct effect on their travel behavior postmigration. The implication of this is that travel products and services aimed at targeting migrant populations, such as Korean Australians, need to be more varied than simply offering a one-size-fits-all solution. Tourism operators in particular must be mindful that, despite the common culture held by migrants from a particular country to their new homeland, Korean migrants to Australia in this case, the types of experiences these travelers demand in their postmigration life tend to differ considerably depending on how they have acculturated into their new country.

While the original culture of migrants undoubtedly remains strong for many migrants, in Australia or elsewhere, this research has also reiterated the significant impact that mass media exposure can have on changing the lifestyle of groups when they migrate. In this instance, it is evident that Korean migrants who had experienced greater levels of social interaction with Australians in general and who had also been more exposed to local mass media, whether through choice or necessity, dem- onstrated a stronger interest in travel generally and specifically more so in cultural attractions, entertainment, and independent travel opportunities. On the other hand, there is definitely a niche market for tourism operators to target group-based travel packages that are aimed at allowing Koreans to mix with other Koreans in their new host country, as desired by the segment titled "Korean Socializers and Sports Seekers" in this study.

In conclusion, this study has demonstrated that there is undoubtedly a link between the levels of acculturation experienced by migrants to a new country and the type of travel lifestyle, and consequently travel preferences, they adopt postmigration. Clearly, these results can only be directly used to explain the experience of the population of interest-that is, Korean migrants in Australia. Further studies in other countries and cultural contexts will determine if such findings also apply in other contexts. What is most important to note, in support of studies in cultural behavior in general, is that it should not be assumed that even though a group of migrants who reside in a country are all of the same origin and demographic profile, that they will tend to want the same type of travel experiences. The degree to which they have acculturated into their new homeland appears to alter travel behaviors to some degree.

A further limitation of the study should be noted at this point. Through the recruitment of respondents via Korean churches and Korean shops in Queensland, it is possible that the study has omitted migrants who have become somewhat detached from their birth country and culture. That is, by surveying respondents who had already demonstrated that they still had an attachment to Korea and the Korean culture by frequenting these locations, there is certainly the potential for some bias to exist towards migrants who were still somewhat active in maintaining their original cultural beliefs. Nevertheless, a reasonably representative cross section of the Korean migrant population appears to have been accessed as reported above.

As with any issue involving "culture," there is a wealth of opportunity for further research into the effect of acculturation on travel behaviors and lifestyles. Studies that seek to gain a deeper understanding of how migrant cultures view the Australian travel industry's advertising and promotion, 
as well as their product offerings, would be of obvious interest to cater for the needs of these residents. Furthermore, from the perspective of trying to improve the travel experiences of migrants in a country such as Australia, it is concerning that approximately one third of all respondents in this study reported that they had experienced some difficulty due to "cultural barriers" when they traveled in Australia. Further research aimed at understanding the source of these cultural barriers when traveling is required so that the needs of these residents are met when they travel and so that traveling in Australia is seen as a positive aspect of their lifestyle. Understanding the issues of acculturation and travel lifestyle will not only provide further marketing opportunities for tourism operators and marketers to target this specific market niche, but it will also assist in reducing the barriers experienced in local travel by immigrant residents.

\section{References}

Andereck, K. L., \& Caldwell, L. L. (1994). Variable selection in tourism market segmentation models. Journal of Travel Research, 33(2), 40-46.

Australian Bureau of Statistics. (2001). Census of population and housing Australia. Canberra: Author.

Barker, M., Page, S. J., \& Meyer, D. (2003). Urban visitor perceptions of safety during a special event. Journal of Travel Research, 41(4), 355-361.

Bartlett, M. S. (1954). A note on the multiplying factors for various $\chi^{2}$ approximations. Journal of the Royal Statistical Society, 16(B), 296-298.

Boekestijn, C. (1988). Intercultural migration and the development of personal identity: The dilemma between identity maintenance and cultural adaptation. International Journal of Intercultural Relations, 12, 83-105.

Bruns $\varnothing$, K., Scholderer, J., \& Grunert, K. G. (2004). Closing the gap between values and behaviour-a meansend theory of lifestyle. Journal of Business Research, 57(6), 665-670.

Chen, J. S., \& Hsu, C. H. C. (2000). Measurement of Korean tourists' perceived images of overseas destinations. Journal of Travel Research, 38(4), 411-416.

Darden, W. R., \& Perreault, Jr., William D. (1975). A multivariate analysis of media exposure and vacation behavior with life style covariates. Journal of Consumer Research, 2(2), 93-103.

Department of Immigration and Multicultural and Indigenous Affairs. (2005a). Population flows: Immigration aspects 2003-04 edition. Retrieved 10. June 2005 from http://www.immi.gov.au/media/publications/statistics/ popflows2003-4/index.htm

Department of Immigration and Multicultural and Indigenous Affairs. (2005b). Immigration update, June 2004.
Retrieved 10 June 2005 from http://www.immi.gov.au/ media/publications/statistics/index.htm

Gladwell, N. J. (1990). A psychographic and sociodemographic analysis of state park inn users. Journal of Travel Research, 28(4), 15-20.

Gountas, J. Y., \& Gountas, S. C. (2001). A new psychographic segmentation method using Jungian MBTI variables in the tourism industry. In C. J. A. Mazanec, G. I. Crouch, J. R. B. Ritchie, \& A. G. Woodside (Eds.), Consumer psychology of tourism, hospitality and leisure (pp. 215-229). New York: CABI Publishing.

Hair, J. F., Anderson, R. E., Tatham, R. L., \& Black, W. C. (1998). Multivariate data analysis (5th ed.). Upper Saddle River, NJ: Prentice Hall.

Henry, W. A. (1976). Cultural values do correlate with consumer behaviour. Journal of Marketing Research, 13, 121-127.

Hyun, K. J. (2001). Sociocultural change and traditional values: Confucian values among Koreans and Korean Americans. International Journal of Intercultural Relations, 25(2), 203-229.

Irwin, P., Gartner, W., \& Phelps, C. (1990). MexicanAmerican/Anglo cultural differences as recreation style determinants. Leisure Sciences, 12, 335-348.

Iverson, T. J. (1997). Decision timing: A comparison of Korean and Japanese travellers. International Journal of Hospitality Management, 16(2), 209-219.

Johansson, T., \& Miegel, F. (1992). Do the right thing: Lifestyle and identity in contemporary youth culture. Stockholm: Almqvist \& Wiksell International.

Johns, N., \& Gyimóthy, S. (2002). Market segmentation and the prediction of tourist behaviour: The case of Bornholm, Denmark. Journal of Travel Research, 40(3), 316-327.

Juniu, S. (2000). The impact of immigration: Leisure experience in the lives of South American immigrants. Journal of Leisure Research, 32(3), 358-381.

Kamo, Y., \& Zhou, M. (1994). Living arrangements of elderly Chinese and Japanese in the United States. Journal of Marriage and the Family, 56, 544-558.

Kim, C., Laroche, M., \& Tomiuk, M. A. (2001). A measure of acculturation for Italian Canadians: Scale development and construct validation. International Journal of Intercultural Relations, 25(6), 607-637.

Klemm, M. S. (2002). Tourism and ethnic minorities in Bradford: The invisible segment. Journal of Travel Research, 41(1), 85-91.

Kozak, M. (2002). Comparative analysis of tourist motivations by nationality and destinations. Tourism Management, 23(3), 221-232.

Lawson, R., Thyne, M., Young, T., \& Juric, B. (1999). Developing travel lifestyles: A New Zealand example. In A. Pizam \& Y. Mansford (Eds.), Consumer behavior in travel and tourism (pp. 449-479). New York: The Haworth Hospitality Press.

Lee, C.-K., Lee, Y-K., \& Wicks, B. E. (2004). Segmentation of festival motivation by nationality and satisfaction. Tourism Management, 25(1), 61-70.

Lehto, X. Y., Morrison, A. M., \& O’Leary, J. T. (2001). Does the visiting friends and relatives' typology make 
a difference? A study of the international VFR market to the United States. Journal of Travel Research, 40(2), 201-212.

Manrai, L. A., \& Manrai, A. K. (1995). Effects of culturalcontext, gender, and acculturation on perceptions of work versus social/leisure time usage. Journal of Business Research, 32(2), 115-128.

March, R. (1997). Diversity in Asian outbound travel industries: A comparison between Indonesia, Thailand, Taiwan, South Korea and Japan. International Journal of Hospitality Management, 16(2), 231-238.

McCracken, G. (1988). Culture and consumption: New approaches to the symbolic character of consumer goods and activities. Bloomington and Indianapolis: Indiana University Press.

McCullough, J., Tan, C. T., \& Wong, J. (1986). Effects of stereotyping in cross cultural research: Are the Chinese really Chinese? Advances in Consumer Research, 13, 576-578.

Middleton, V. T. C., \& Clarke, J. (2001). Marketing in travel and tourism (3rd ed.). Oxford: ButterworthHeinemann.

Milman, A. (1991). The role of theme parks as a leisure activity for local communities. Journal of Travel Research, 29(3), 11-16.

Murphy, A. E. (2003). Illustrating the utility of a modified gap analysis as a regional tourism planning tool: Case study of potential Japanese and German travelers to the Cowichan region. Journal of Travel Research, 41(4), 400-409.

Mykletun, R. J., Crotts, J. C., \& Mykletun, A. (2001). Positioning an island destination in the peripheral area of the Baltics: A flexible approach to market segmentation. Tourism Management, 22(5), 493-500.

Perreault, W. D., Darden, D. K., \& Darden, W. R. (1977). A psychographic classification of vacation life styles. Journal of Leisure Research, 9(1), 208-223.

Pizam, A., \& Jeong, G-H. (1996). Cross-cultural tourist behaviour. Tourism Management, 17(4), 277-286.

Pizam, A., Jeong, G-H., Reichel, A., Boemmel, H., Lusson, J. M., Steynberg, L., State-Costache, O., Volo, S., Kroesbacher, C., Kucerova, J., \& Montmany, N. (2004). The relationship between risk-taking, sensation-seeking, and the tourist behaviour of young adults: A crosscultural study. Journal of Travel Research, 42(3), 251260.

Pizam, A., \& Sussmann, S. (1995). Does nationality affect tourist behaviour? Annals of Tourism Research, 22(4), 901-917.

Prentice, R. C., Witt, S. F., \& Hamer, C. (1998). Tourism as experience: The case of heritage parks. Annals of Tourism Research, 25(1), 1-24.
Przeclawski, K. (1988). Tourism and transformations in the style of living. Proceedings of the Leisure Studies Association 2nd International Conference (pp. 36-42). Eastbourne, England: LSA Publications.

Reisinger, Y., \& Turner, L. (1998). Cross-cultural differences in tourism: A strategy for tourism marketers. Journal of Travel \& Tourism Marketing, 7(4), 79-106.

Reisinger, Y., \& Turner, L. (1999). A cultural analysis of Japanese tourists: Challenges for tourism marketers. $E u$ ropean Journal of Marketing, 33(11/12), 1203-1227.

Reisinger, Y., \& Turner, L. (2002a). Cultural differences between Asian tourist markets and Australian hosts, part 1. Journal of Travel Research, 40(3), 295-315.

Reisinger, Y., \& Turner, L. (2002b). Cultural differences between Asian tourist markets and Australian hosts, part 2. Journal of Travel Research, 40(4), 374-384.

Reisinger, Y., \& Turner, L. (2003). Cross-cultural behaviour in tourism: Concepts and analysis. Oxford: Butterworth-Heinemann.

Salant, T., \& Lauderdale, D. S. (2003). Measuring culture: A critical review of acculturation and health in Asian immigrant populations. Social Science \& Medicine, 57, 71-90.

Schul, P., \& Crompton, J. L. (1983). Search behaviour of international vacationer: Travel-specific lifestyle and sociodemographic variables. Journal of Travel Research, 22(2), 25-30.

Sherry Jr., J. F. (1986). The cultural perspective in consumer research. Advances in Consumer Research, 13, $573-575$.

Silverberg, K. E., Backman, S. J., \& Backman, K. F. (1996). A preliminary investigation into the psychographics of nature-based travelers to the Southeastern United States. Journal of Travel Research, 35(2), 19-28.

Stodolska, M. (1998). Assimilation and leisure constraints: Dynamics of constraints on leisure in immigrant populations. Journal of Leisure Research, 30(4), 521-551.

Tan, C. T., \& McCullough, J. (1985). Relating ethnic attitudes and consumption values in an Asian context. Advances in Consumer Research, 12, 122-125.

Tierney, P. T., Dahl, R., \& Chavez, D. (2001). Cultural diversity in use of undeveloped natural areas by Los Angeles county residents. Tourism Management, 22(3), 271-277.

Tse, D. K., Wong, J. K., \& Tan, C. T. (1988). Towards some standardised cross cultural consumption values. Advances in Consumer Research, 15, 387-395.

Weinstein, A. (1994). Market segmentation. New York: McGraw-Hill. 